\title{
Brain renin-angiotensin system in the nexus of hypertension and aging
}

\author{
Amy C Arnold, Patricia E Gallagher and Debra I Diz \\ Aging is associated with an imbalance in sympathetic and parasympathetic outflow to cardiovascular effector organs. \\ This autonomic imbalance contributes to the decline in cardiovagal baroreceptor reflex function during aging, which allows \\ for unrestrained activation of the sympathetic nervous system to negatively impact resting systolic blood pressure and its \\ variability. Further, impaired baroreflex function can contribute to the development of insulin resistance and other features \\ of the metabolic syndrome during aging through overlap in autonomic neural pathways that regulate both cardiovascular and \\ metabolic functions. Increasing evidence supports a widespread influence of the renin-angiotensin system (RAS) on both \\ sympathetic and parasympathetic activity through receptors distributed to peripheral and central sites of action. Indeed, \\ therapeutic interventions to block the RAS are well established for the treatment of hypertension in elderly patients, and \\ reduce the incidence of new-onset diabetes in clinical trials. Further, RAS blockade increases lifespan and improves numerous \\ age-related pathologies in rodents, often independent of blood pressure. The beneficial effects of these interventions are at \\ least in part attributed to suppression of angiotensin II formed locally within the brain. In particular, recent insights from \\ transgenic rodents provide evidence that long-term alteration in the brain RAS modulates the balance between angiotensin II \\ and angiotensin-(1-7), and related intracellular signaling pathways, to influence cardiovascular and metabolic function in the \\ context of hypertension and aging.
}

Hypertension Research (2013) 36, 5-13; doi:10.1038/hr.2012.161; published online 18 October 2012

Keywords: autonomic nervous system; brain; cardiovascular; metabolic; transgenic rats

\section{INTRODUCTION}

Aging is associated with numerous changes in autonomic regulation of the cardiovascular system that predispose individuals to hypertension and related pathologies. The hypertension in aged individuals is primarily due to elevations in systolic blood pressure, attributed to reductions in vascular distensibility and an imbalance in the autonomic nervous system (Figure 1). ${ }^{1,2}$ Arterial baroreceptor reflex function also declines during aging, an effect permissive to reductions in heart-rate variability, increases in sympathetic outflow and subsequent elevations in blood pressure. ${ }^{3}$ Moreover, baroreflex dysfunction can contribute to the insulin resistance that accompanies hypertension, due to substantial overlap in autonomic mechanisms involved in the regulation of cardiovascular and metabolic functions. Understanding the mechanisms underlying autonomic imbalance, and baroreflex dysfunction, during aging is critical given the increasing proportion of elderly individuals worldwide. In this regard, the reninangiotensin system (RAS) influences sympathetic and parasympathetic arms of the autonomic nervous system to promote the development of hypertension and related features of the metabolic syndrome, especially during aging. The present review will describe recent advances in the role of the RAS in the constellation of metabolic and cardiovascular changes that occur with aging, with a focus on the contribution of brain angiotensins to these derangements.

\section{CARDIOVASCULAR AND METABOLIC ACTIONS OF THE CLASSICAL CIRCULATING RAS}

The RAS is intimately involved in regulation of the cardiovascular system, under normal conditions and in pathophysiologic states, through receptors widely distributed to peripheral and central sites of action. Angiotensin II acts at $\mathrm{AT}_{1}$ receptors in the vasculature to promote vasoconstriction and at sites within the central nervous system to stimulate sympathetic outflow, impair the baroreflex sensitivity for heart rate control, promote release of catecholamines and aldosterone and initiate sodium retention through excitation of renal efferent nerves. ${ }^{4,5}$ These collective actions are permissive to increases in blood pressure and have an important role in the development and maintenance of hypertension. The importance of angiotensin II actions to hypertension is further illustrated by the finding that genetic deletion of $\mathrm{AT}_{1 \mathrm{~A}}$ receptors or angiotensin converting enzyme (ACE) significantly lowers systolic blood pressure in

The Hypertension and Vascular Research Center, Departments of General Surgery and Physiology and Pharmacology, Wake Forest University School of Medicine, WinstonSalem, NC, USA

Correspondence: Professor DI Diz, The Hypertension and Vascular Research Center, Departments of General Surgery and Physiology and Pharmacology, Wake Forest University School of Medicine, Medical Center Boulevard, Winston-Salem, NC 27157-1032, USA.

E-mail: ddiz@wakehealth.edu

Received 27 June 2012; revised 2 August 2012; accepted 30 August 2012; published online 18 October 2012 
An Imbalance in the ANS during Aging favors Hypertension and Target Organ Damage

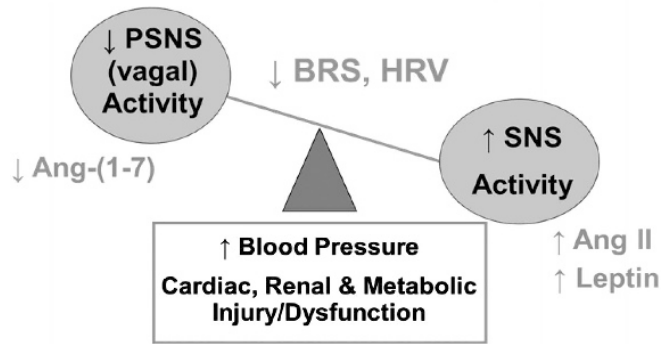

Figure 1 Schematic of proposed features associated with the imbalance in the autonomic nervous system during aging. During aging there is a shift in the balance of the autonomic nervous system (ANS) towards the sympathetic nervous system (SNS). This may be influenced by circulating or local brain levels of angiotensin (Ang) II and leptin. The lower activity of the parasympathetic nervous system (PSNS) is proposed to result at least in part from an age-related decline in Ang-(1-7). Lower Ang-(1-7) and higher Ang II or leptin in the brain medulla would predispose to a decline in baroreceptor reflex sensitivity (BRS) for control of heart rate and heart rate variability (HRV), both of which are associated with aging. Moreover, impairments in BRS and HRV can contribute to target organ damage, including metabolic dysfunction, with or without an increase in blood pressure. A full color version of this figure is available at the Hypertension Research journal online.

mice. ${ }^{6,7}$ As such, the use of $\mathrm{ACE}$ inhibitors and $\mathrm{AT}_{1}$ receptor blockers (ARBs) to prevent the formation and actions of angiotensin II, respectively, is well established for the treatment of essential hypertension and other cardiovascular diseases. ${ }^{8}$ In addition to lowering blood pressure, these drugs reset the baroreflex setpoint to normotensive levels and improve the baroreflex sensitivity for control of heart rate, an important marker of parasympathetic tone mediated within the nucleus tractus solitarius (nTS) in the dorsal medulla oblongata. Importantly, these therapies also shift the balance of the RAS to increase levels of the heptapeptide angiotensin-(1-7), which may contribute to many of the above mentioned beneficial effects of these treatments.

Angiotensin-(1-7) is formed by cleavage of either angiotensin I by various endopeptidases or from angiotensin II by ACE2. The actions of angiotensin-(1-7) at mas receptors induce vasodilation and facilitation of baroreflex sensitivity, to generally oppose the deleterious cardiovascular effects of angiotensin II., ${ }^{9}$ Infusion of angiotensin-(1-7) transiently lowers blood pressure with sustained improvement in baroreflex sensitivity in hypertensive rodents ${ }^{11}$ and improves cardiovascular function at least in part independent of hypertension in animal models of type 2 diabetes. ${ }^{12,13}$ In contrast, genetic deletion of the angiotensin-(1-7) mas receptor results in increases in resting blood pressure and lower baroreflex sensitivity, with normal resting heart rate. ${ }^{14}$ Further, mice with a genetic deficiency of ACE2 can exhibit modest systolic hypertension, cardiac autonomic imbalance, central oxidative stress, vascular inflammation and left ventricular hypertrophy in part associated with increased age, depending on the genetic background. ${ }^{15-17}$ A chronic peptide imbalance in which angiotensin II is increased and angiotensin-(1-7) is decreased has been implicated in aging and in several animal models of hypertension. ${ }^{18-21}$ In addition, urinary angiotensin-(1-7) levels are reduced in essential hypertension $^{22}$ and an imbalance in enzyme activity in which ACE is increased and ACE2 is decreased is evident in the kidneys of hypertensive patient $\mathrm{s}^{23}$ and adult sheep with fetal-programmed hypertension..$^{24,25}$ These findings suggest that the balance of angiotensin II and angiotensin-(1-7), and associated levels of
ACE and ACE2 enzyme activities, may be important for determining prevailing cardiovascular function.

Angiotensin receptors are also distributed to peripheral organs involved in the regulation of metabolic function. Components of the circulating RAS such as angiotensinogen, renin, ACE and aldosterone are increased in obese subjects. ${ }^{26,27}$ Angiotensinogen levels are also increased in adipose tissue of obese humans and rodents, ${ }^{28,29}$ and overexpression of this precursor specifically in adipose tissue increases body weight and fat mass in transgenic rodents. ${ }^{30,31}$ Conversely, weight loss results in reductions in circulating levels of angiotensinogen, renin and aldosterone, ${ }^{32}$ suggesting an adipocytederived tissue source in obesity. Individuals with polymorphisms in ACE or angiotensinogen genes have higher levels of blood pressure, body weight and abdominal adiposity, particularly in aged individuals. $^{33,34}$ In contrast, pharmacological and genetic approaches to block RAS pathways improve metabolic function, insulin regulation and glycemic control. For example, chronic pharmacologic inhibition of renin or ACE prevents features of the metabolic syndrome in obese rodents. ${ }^{35-38}$ Further, transgenic rodents with global deletion of various components of the RAS including angiotensinogen, renin, $\mathrm{ACE}$ or the $\mathrm{AT}_{1 \mathrm{~A}}$ receptor are lean and resistant to diet-induced obesity, due to changes in metabolic pathways controlling adipocyte development, lipolysis, locomotor activity and metabolic rate. ${ }^{39-42}$

It is well established that circulating angiotensin II levels are increased in metabolic diseases, similar to findings in essential hypertension, and correlate closely to markers of insulin resistance. $^{26,27}$ As recently reviewed, angiotensin II can promote insulin resistance through multiple mechanisms including increasing levels of oxidative stress, stimulating aldosterone release, reducing levels of the insulin-sensitizing hormone adiponectin, interference with intracellular insulin signaling pathways and direct suppression of insulin secretion from pancreatic $\beta$-cells. ${ }^{26,43}$ However, under normal conditions the effects of angiotensin II to stimulate sympathetic outflow and reduce skeletal muscle blood flow or to drive thermogenesis appear to predominate. Chronic subcutaneous infusion of low-dose angiotensin II reduces body weight, decreases food intake and increases resting metabolic rate in normotensive rodents. ${ }^{44,45}$ Further, the contribution of angiotensin II to metabolic function in healthy humans is not clear as acute infusion can either improve or impair insulin sensitivity depending on the glycemic conditions. ${ }^{46,47}$

Regardless, chronic administration of ACE inhibitors and ARBs prevents the deleterious effects of angiotensin II on insulin regulation in obese rodents. In addition, large randomized clinical trials provide evidence that these therapies reduce the incidence of new-onset diabetes in high-risk populations. ${ }^{36,37,48-50}$ The beneficial effects of RAS blockade on insulin action may be in part due to an increase in angiotensin-(1-7) levels. Recent studies show that angiotensin-(1-7) stimulates phosphorylation of insulin intracellular signaling pathway components in extra-cardiac tissues and prevents effects of angiotensin II to uncouple insulin signaling. ${ }^{51}$ Genetic deletion of the angiotensin-(1-7) mas receptor results in a metabolic syndrome phenotype in rodents characterized by dyslipidemia and impairments in insulin action, in the absence of changes in body weight or food intake. $^{52}$ Further, ACE2-deficient mice have higher resting blood glucose levels. ${ }^{53}$ Conversely, transgenic mice with only a twofold elevation in endogenous angiotensin-(1-7) levels are lean and have improved insulin sensitivity. ${ }^{54}$ Overexpression of ACE2 in the pancreas is also reported to attenuate the hyperglycemia and insulin resistance in a diabetic state via a mechanism involving angiotensin(1-7). ${ }^{55,56}$ These findings suggest that similar to the cardiovascular 
system, the status of angiotensin II vs. angiotensin-(1-7) in the periphery influences overall metabolic function, and that systemic blockade of angiotensin II or elevation of angiotensin-(1-7) pathways preserves cardiovascular and metabolic function, particularly in the context of hypertension and obesity.

\section{EFFECTS OF RAS BLOCKADE ON CARDIOVASCULAR AND METABOLIC DERANGEMENTS DURING AGING}

The decline in arterial baroreceptor reflex function that occurs with aging involves both resetting of the reflex setpoint to higher levels of pressure and reduced sensitivity for heart rate control., ${ }^{2,3}$ The reduction in the baroreflex sensitivity can manifest from impairment of afferent, central neuronal or efferent regulatory mechanisms. In older Sprague-Dawley rats, vascular responses to phenylephrine are reduced, which could result in inadequate stretchinduced activation of afferent baroreflex pathways that synapse in the nTS. ${ }^{57}$ In addition, neurotransmitter actions within the nTS, including catecholaminergic and glutamate-GABA pathways that regulate reflex bradycardia, are altered during hypertension and aging in rodents. ${ }^{58,59}$ In human subjects, preliminary data also support a relationship between the lower baroreflex sensitivity in healthy older individuals and glutamate metabolism in dorsal medulla. ${ }^{60}$ Baroreflex dysfunction is permissive to the development of systolic hypertension and insulin resistance that occurs with aging and reduces heart rate variability to increase risk for cardiovascular morbidity and all-cause mortality. ${ }^{3,61}$ Polymorphisms of the ACE gene increase risk of myocardial infarction in an aging cohort ${ }^{62}$ and ACE inhibitors and ARBs effectively lower blood pressure, improve baroreflex function and reduce risk for diabetes in elderly hypertensive patients. ${ }^{48,63}$ These collective findings suggest an important role for the balance of angiotensin II vs. angiotensin(1-7) axes in the cardiovascular and metabolic changes that occur with aging in clinical populations.

Chronic ACE inhibition or $\mathrm{AT}_{1}$ receptor blockade also extends lifespan and improves or prevents deficits in cardiovascular, metabolic and renal function during aging in normotensive and hypertensive rodents. ${ }^{21,64} \mathrm{~A}$ recent study shows that global disruption of the $\mathrm{AT}_{1 \mathrm{~A}}$ receptor promotes longevity in mice through attenuation of agerelated mitochondrial loss and oxidative stress as well as upregulation of prosurvival genes. ${ }^{65}$ During aging, $\mathrm{AT}_{1 \mathrm{~A}}$ receptor knockout mice also exhibit a lean phenotype and maintenance of bone mass and cerebral endothelial function. ${ }^{66,67}$ These studies illustrate a deleterious role for both $\mathrm{ACE}$ and the $\mathrm{AT}_{1}$ receptor in age-related pathologies. In contrast, emerging evidence suggests a protective role for ACE2 against angiotensin II-dependent cardiovascular and metabolic changes with aging. In animal models of advanced stage diabetes, renal ACE2 expression and activity are reduced and are associated with markers of renal injury. The progression of diabetic nephropathy with age and associated oxidative stress can be attenuated in these animals by treatment with recombinant ACE2. ${ }^{68}$ Further, global genetic deficiency of ACE2 results in dilated cardiomyopathy and exaggerated dysautonomia and hypertension during aging, which may be attributed to increases in oxidative stress and inflammation. ${ }^{69}$

Importantly, the beneficial effects of systemic RAS blockade on agerelated pathologies are observed even in the absence of changes in blood pressure. In Fischer 344 rats, long-term oral ARB administration lowers circulating insulin and leptin levels, improves insulin sensitivity, lowers body weight and prevents activation of the intrarenal RAS and renal fibrosis independent of pressure. ${ }^{70}$ These data suggest a beneficial effect of RAS blockade on metabolic function and on indices of renal injury in the absence of cardiovascular effects. Recent studies show that Fischer 344 rats also exhibit increases in renin and angiotensinogen and decreases in leptin receptor and PI3K mRNA in dorsal medulla during aging. ${ }^{71}$ Chronic RAS blockade shifted the pattern of gene expression in dorsal medulla of these animals in a direction that would favor angiotensin-(1-7) production as well as promote signaling pathways utilized by leptin and insulin for beneficial metabolic effects. Whether parallel changes in protein expression or enzyme activity occur needs to be assessed. However, these alterations are consistent with the overall improvement in cardiovascular and metabolic function in these animals following RAS blockade.

The precise mechanisms underlying the beneficial effects of RAS blockade or genetic deletion during aging remain unclear. First, it is not understood whether these effects are mediated by peripheral vs. central sites of action. Although chronic pharmacologic treatment or global deletion of RAS receptors and enzymes should influence brain regions involved in cardiovascular and metabolic control, these interventions may also prevent local angiotensin II actions in effector organs, such as heart, kidneys, skeletal muscle, liver and pancreas. In fact, plasma renin activity, renin responsiveness and circulating angiotensin II levels decrease with age, ${ }^{72}$ suggesting that the beneficial effects of RAS blockade are in part mediated by effects in local tissues. Second, ACE inhibitors and ARBs shift the balance of the RAS to increase angiotensin-(1-7) levels. ${ }^{9}$ The elevation or maintenance of circulating angiotensin-(1-7) achieved by such therapies may contribute to beneficial effects during aging independent of angiotensin II levels. ${ }^{73}$ Alternately, maintenance of angiotensin-(1-7) levels in brain via these treatments may be especially important during aging, where deficiency of the peptide in the brainstem contributes to impairments in baroreflex sensitivity. ${ }^{57}$ As evidence that systemic treatments may increase brain angiotensin-(1-7) levels, improvement of baroreflex sensitivity by chronic oral enalapril treatment is reversed by intracerebroventricular administration of a mas receptor antagonist in a model of renovascular hypertension. ${ }^{74}$

\section{THE BRAIN RAS, HYPERTENSION AND AGING}

In particular, the brain RAS has been implicated as an important contributor to hypertension and related comorbidities during aging. All components required for the formation and degradation of angiotensin peptides are present in brain and are regulated independent of the circulation. ${ }^{4}$ Angiotensin receptors are highly expressed in circumventricular organs and in all synaptic relays of sympathetic and parasympathetic neural pathways.,75 Similar to the periphery, angiotensin II acts at central $\mathrm{AT}_{1}$ receptors to stimulate sympathetic activity and impair baroreceptor pathways originating in the nTS that restrain sympathetic outflow. ${ }^{4,76-78}$ Brain-specific administration of ACE inhibitors and ARBs lowers blood pressure in hypertensive rodents. ${ }^{4}$ These interventions often improve baroreflex sensitivity in normotensive and hypertensive animals, revealing a tonic role for angiotensin II endogenous to the brain, particularly in the nTS, for suppression of baroreflex function. ${ }^{79}$ In contrast, blockade of mas receptors impairs baroreflex sensitivity in the nTS suggesting that local angiotensin-(1-7) facilitates baroreflex function. ${ }^{57,80}$ However, this peptide can exert similar pressor or depressor responses relative to angiotensin II when microinjected into specific brain nuclei. ${ }^{76,81}$ Microinjection of an ACE2 inhibitor in the nTS also impairs the baroreflex sensitivity in younger rats, to a similar level as mas receptor blockade, implicating this enzymatic pathway as an important source of angiotensin-(1-7) for baroreflex modulation. ${ }^{82}$ In addition, central overexpression of ACE2 lowers blood pressure, restores autonomic 
function, increases nitric oxide and prevents the development of angiotensin II hypertension in rodents. ${ }^{56}$ These collective findings suggest that the balance between angiotensin II and angiotensin-(1-7) within the brain also influences resting blood pressure and cardiovagal baroreflex function.

Aging in normotensive rats is characterized by increases in blood pressure and impairment of baroreflex sensitivity for control of heart rate. ${ }^{57,83,84}$ Functional studies provide evidence that blockade of angiotensin II receptors within the nTS improves the baroreflex sensitivity to a similar extent in older vs. younger Sprague-Dawley rats. ${ }^{57}$ In contrast, blockade of angiotensin-(1-7) receptors impairs the baroreflex sensitivity in younger but not older Sprague-Dawley rats suggesting loss of angiotensin-(1-7) actions for baroreflex modulation during aging. The loss of angiotensin-(1-7) actions is associated with reduced neprilysin enzyme gene expression in dorsal medulla of older rats, perhaps indicating reduced formation of the peptide with aging. However, there were no differences in ACE, ACE2 or mas receptor mRNA between younger and older animals. ${ }^{57}$ These data may suggest that deficiency of angiotensin-(1-7), to counteract angiotensin II actions, contributes to the decline in baroreflex function during aging.

The use of transgenic rodents with varying degrees of brain RAS activation has revealed important insights into the contribution of brain angiotensins to the development of hypertension. A wellestablished model of overexpression of the brain RAS, the transgenic (mRen2)27 rat, was created by insertion of the mouse renin-2 gene into the rat genome. ${ }^{85}$ As a result, these animals have high adrenal and brain tissue levels of angiotensin II, modest elevations in plasma angiotensin II and develop fulminant hypertension with impairment of baroreflex sensitivity at an early age. Similar to older SpragueDawley rats, the impairment in baroreflex sensitivity even in younger (mRen2)27 rats is associated with loss of central angiotensin-(1-7) actions. ${ }^{18,20}$ Acute nTS microinjection of an ARB does not improve baroreflex sensitivity in these animals. ${ }^{86}$ Interestingly, chronic 2-week intracerebroventricular infusion of an $\mathrm{AT}_{1}$ receptor antagonist did not improve vagal components of the baroreflex sensitivity in (mRen2)27 rats even though the treatment normalized blood pressure. ${ }^{87}$ In contrast, acute treatment with an ACE inhibitor in the nTS, intracisternal gene transfer replacement of angiotensin-(1-7) or 2-week intracerebroventricular infusion of angiotensin-(1-7) restores the baroreflex sensitivity to levels similar to normotensive Sprague-Dawley rats. ${ }^{18,86,87}$ In these studies, the improvement in autonomic balance occurred independent of changes in blood pressure, further dissociating these two effects. One possible contributor to the improvement in autonomic balance with angiotensin(1-7) treatment is restoration of signaling pathways in the dorsal medulla, as increases in the phosphatases MKP-1 and protein tyrosine phosphatase $1 \mathrm{~b}$ (PTP1b) were observed. ${ }^{18}$ In fact, pharmacological blockade of PI3K selectively lowers blood pressure in (mRen2)27 and spontaneously hypertensive rats and improves baroreflex function in (mRen2)27 rats. ${ }^{88,89}$ This finding suggests that the hypertensive phenotype is accompanied by enhanced PI3K signaling, an intracellular pathway that is activated by various peptides including angiotensin II, insulin and leptin. During aging, cardiovascular function dramatically declines in hypertensive rodents and is confounded by cardiac fibrosis, left ventricular hypertrophy and the development of heart failure in the face of persistent hypertension. ${ }^{84}$ These animals also have a shorter lifespan relative to the SpragueDawley control strain. ${ }^{21}$ Whether replacement of angiotensin-(1-7) or manipulation of signaling pathways within the dorsal medulla can restore autonomic balance or prevent target organ damage during aging in these animals has not been established. A similar cardiovascular phenotype is observed in sRA double transgenic mice with neuronal overexpression of human renin and angiotensinogen. These mice exhibit robust hypertension, polydipsia and polyuria despite suppression of the circulating RAS. ${ }^{90}$ However, there is no information available for these mice during aging.

The transgenic ASrAOGEN rat represents a model of healthy aging in the face of underexpression of the endogenous brain RAS. ASrAOGEN rats were created by insertion of an antisense oligonucleotide to angiotensinogen driven specifically to glial cells, ${ }^{91}$ the primary source for this precursor in brain. ${ }^{92}$ These animals have $>90 \%$ reduction of brain angiotensinogen levels and subsequent decreases in brain tissue angiotensin peptide content, with no differences in circulating RAS components. ${ }^{91}$ However, preliminary studies show intact angiotensin II and angiotensin-(1-7) immunoreactivity in neuronal cells of these animals, consistent with extra-glial angiotensinogen production. ${ }^{93}$ ASrAOGEN rats exhibit mild hypotension due to reductions in glia-derived angiotensin peptides and plasma vasopressin levels. ${ }^{91}$ These animals have higher baroreflex sensitivity for control of heart rate, and improvements in parasympathetic tone to the heart, relative to Sprague-Dawley rats even under anesthesia. ${ }^{94-96}$ During aging, ASrAOGEN rats have an extended lifespan and are protected from declines in cardiovascular function. ${ }^{21}$ Resting pressure and heart rate are similar in younger and older ASrAOGEN rats, and are lower at both ages relative to Sprague-Dawley and (mRen2)27 animals. ${ }^{84}$ Although there is some impairment in baroreflex function in conscious older animals, the sensitivity is reduced to a similar level as younger SpragueDawley rats. ${ }^{21,97}$ In both younger and older ASrAOGEN rats, nTS microinjection of candesartan does not alter the baroreflex sensitivity, suggesting that angiotensin II derived from a glial source of angiotensinogen participates in baroreflex modulation..$^{95,97}$ Similar observations with respect to the glial source of angiotensin II for baroreflex inhibition are evident in double transgenic mice in which glial, but not neuronal, overexpression of renin and angiotensinogen impairs the baroreflex sensitivity. ${ }^{98}$ Blockade of mas receptors in the nTS impairs the baroreflex sensitivity to a similar extent in younger and older ASrAOGEN rats, ${ }^{95,97}$ which is opposite to the deficiency of angiotensin-(1-7) actions observed in older Sprague-Dawley rats. ${ }^{57}$ This finding suggests that angiotensin-(1-7) derived from a non-glial source of angiotensinogen is an important mechanism contributing to preservation of baroreflex function during aging.

Finally, although not a focus of this review, the peripheral and brain RAS have been implicated in numerous age-related changes independent of control of hypertension. Systemic administration of ACE inhibitors and ARBs in normotensive subjects protects against age-related declines in mitochondrial capacity, cognition, learning, memory and physical performance. ${ }^{99-101}$ Treatment with more lipophilic ACE inhibitors appears better at preventing age-associated declines in cognitive function, despite similar blood pressure lowering effects. ${ }^{102}$ Emerging evidence suggests that activation of the brain RAS, and angiotensin II in particular, can promote oxidative stress and inflammation to also contribute to the progression of cognitive decline and dopaminergic neuron loss associated with Alzheimer's and Parkinson's diseases, respectively. ${ }^{103,104}$ These findings do not specifically address the independent contribution of blockade of angiotensin II $v s$. elevation of angiotensin-(1-7) to the beneficial actions of treatments, but they do lend further rationale for the use of drugs targeting the RAS in aged populations, especially if the drugs target both central and peripheral sites. 

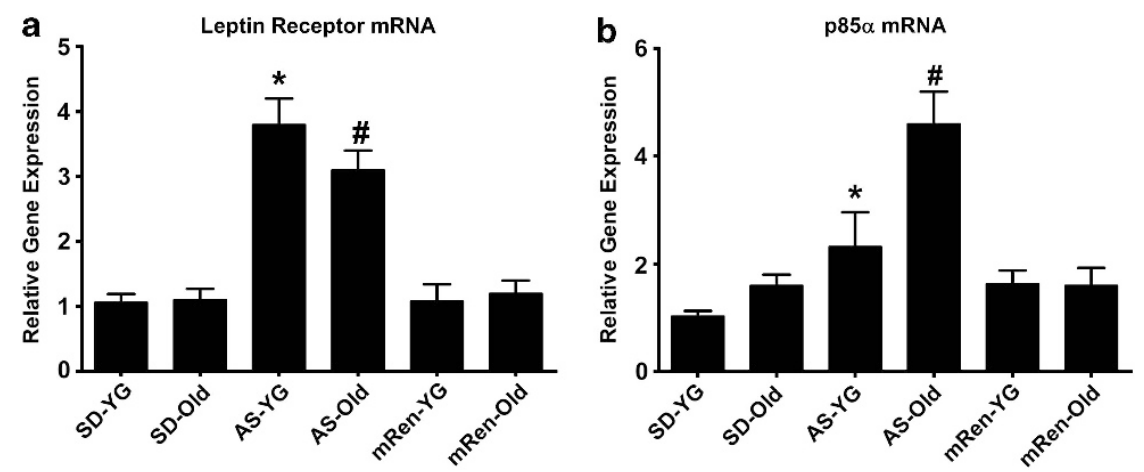

Figure 2 Gene expression for leptin receptor and PI3K in dorsal medulla. Real-time PCR was performed using specific primer/probe sets (Applied Biosystems, Life Technologies Corp., Carlsbad, CA, USA) to measure relative gene expression for the leptin receptor and the p85 $\alpha$ regulatory subunit of the PI3K signaling pathway in dorsal medulla tissue from naive younger (YG, 12-20 weeks) and older (Old, 65-80 weeks) Sprague-Dawley (SD), ASrAOGEN (AS) and (mRen2)27 (mRen2) rats ( $n=6-8$ rats per group). Data are expressed as gene expression relative to the 18S ribosomal RNA control. (a) Leptin receptor mRNA was significantly higher in younger AS vs. younger SD and mRen2 rats $\left({ }^{*} P<0.05\right)$. Leptin receptor gene expression was still higher in older AS rats, relative to other strains, but was reduced compared with younger AS rats $(\# P<0.05)$. (b) PI3K p85 $\alpha$ mRNA was significantly higher in younger AS vs. younger SD rats $\left({ }^{*} P<0.05\right)$. Gene expression for $\mathrm{p} 85 \alpha$ was also significantly higher in older AS rats compared with younger AS and younger and older $\mathrm{SD}$ and $\mathrm{mRen} 2$ rats $(\# P<0.05)$.

\section{THE BRAIN RAS, INSULIN RESISTANCE AND AGING}

Autonomic neural pathways influenced by angiotensin peptides for cardiovascular control are also involved in regulation of metabolic function and glycemic control. ${ }^{105,106}$ In Sprague-Dawley rats, aging is accompanied with increased body weight, hypertension and insulin resistance, which resemble features of the metabolic syndrome in clinical populations. ${ }^{84}$ Inappropriate activation of the brain RAS results in development of insulin resistance as early as 16 weeks of age in hypertensive (mRen2)27 rats. ${ }^{107}$ In younger (mRen2) 27 rats, there does not appear to be elevations in circulating insulin and leptin levels ${ }^{84}$ or in alterations in gene expression for leptin receptor or PI3K intracellular signaling components in dorsal medulla (Figure 2). However, younger rats do exhibit lower mRNA for megalin, an important transporter of leptin and insulin, which is localized to the blood-cerebrospinal fluid barrier (Figure 3a). A similar decrease has been observed in the brain of aged normotensive rats and correlates to impaired leptin uptake. ${ }^{108}$ Interestingly, megalin gene expression is restored in older (mRen2)27 rats (Figure 3a), perhaps due to the finding that body weight, circulating adipokine levels and insulin resistance do not further worsen with age in these animals. ${ }^{84}$ However, suppressor of cytokine signaling 3 (SOCS-3) is elevated in older (mRen2) 27 rats (Figure 3b), an effect which would serve to inhibit activation of metabolic pathways used by insulin and leptin.

During advanced aging, the metabolic profile of Sprague-Dawley rats closely resembles that of (mRen2) 27 rats, ${ }^{84}$ which may reflect an age-related activation of the brain RAS in these animals. In older Sprague-Dawley rats, the development of insulin resistance is associated with a small increase in dorsal medulla gene expression of SOCS-3 (Figure 3b). Similar to SOCS-3, PTP1b serves to inhibit intracellular signaling by leptin and insulin and increased levels of this phosphatase are commonly observed in obesity and type 2 diabetes. ${ }^{109}$ Previous reports have also shown an increase in PTP1b expression in the hypothalamus of aged and obese animals; ${ }^{110}$ however, there are no differences in PTP1b expression in dorsal medulla among younger or older Sprague-Dawley, (mRen2)27 or ASrAOGEN rats when PTPN1 mRNA, the gene encoding the phosphatase, is measured in the brainstem of these animals (Figure 3c). In contrast, ASrAOGEN rats with disruption of gliaderived angiotensinogen maintain lower body weight, fat mass and growth during aging relative to Sprague-Dawley and (mRen2) 27 rats. $^{84}$
In addition, younger and older ASrAOGEN rats have lower fasting insulin and leptin levels and improved responses to oral glucose tolerance testing. ${ }^{107}$ As circulating angiotensin peptides are not altered in these animals, ${ }^{91}$ the beneficial metabolic profile is primarily attributed to alterations in the brain RAS. However, other factors could positively influence metabolic function during aging in these animals including gut hormones, reduced plasma vasopressin and preservation of parasympathetic tone to promote insulin secretion. ASrAOGEN rats have higher gene expression of the leptin receptor and $\mathrm{p} 85 \alpha$ regulatory subunit of $\mathrm{PI} 3 \mathrm{~K}$ in dorsal medulla relative to Sprague-Dawley rats at both older and younger ages (Figure 2). Although there are no alterations in megalin or SOCS-3 gene expression in dorsal medulla of these animals, PTP1b expression is significantly reduced in older ASrAOGEN rats (Figure 3), consistent with the preservation of metabolic sensitivity during aging. These collective data suggest an important role for the brain RAS in the development of metabolic dysfunction during aging, and evidence the importance of glia-derived angiotensinogen to these derangements. Although the relative contribution of brain-derived angiotensin II $v s$. angiotensin-(1-7) to metabolic regulation in hypertension or during aging remains under investigation, preliminary data in (mRen2)27 rats reveal a modest effect of 2 -week intracerebroventricular $\mathrm{AT}_{1}$ receptor blockade on fat mass, with no effect of angiotensin-(1-7) infusion. ${ }^{87}$

It is important to note that in normotensive rodents, chronic central angiotensin II infusion decreases body mass and food intake and increases sympathetically-mediated thermogenesis. ${ }^{44,45}$ Further, sRA mice with neuronal overexpression of the brain RAS have a lean phenotype and are hyperphagic associated with increases in core body temperature and metabolic rate. ${ }^{90}$ Whether this is a result of the accompanying polyuria and polydipsia is not clear. This phenotype however differs from the increased body mass accompanying the hypertension, increased sympathetic nervous system activity and insulin resistance in the (mRen2) 27 rats. ${ }^{84,107}$ The metabolic profile in sRA mice more closely resembles ASrAOGEN rats, in which lower body weight is thought to be due to increases in resting energy expenditure to compensate for increased food intake and lower circulating leptin levels. ${ }^{84}$ Although the exact mechanisms for these disparities are unknown, possible explanations include differences in receptor distribution and sites of action as well as differences in the 
pattern of neuronal $v s$. glial or circulating expression of angiotensin peptides. Although glia-derived angiotensinogen is reduced in ASrAOGEN rats, neuronal sources of angiotensin II appear preserved. ${ }^{93}$ Further, these animals have upregulation of $\mathrm{AT}_{1}$ receptors in

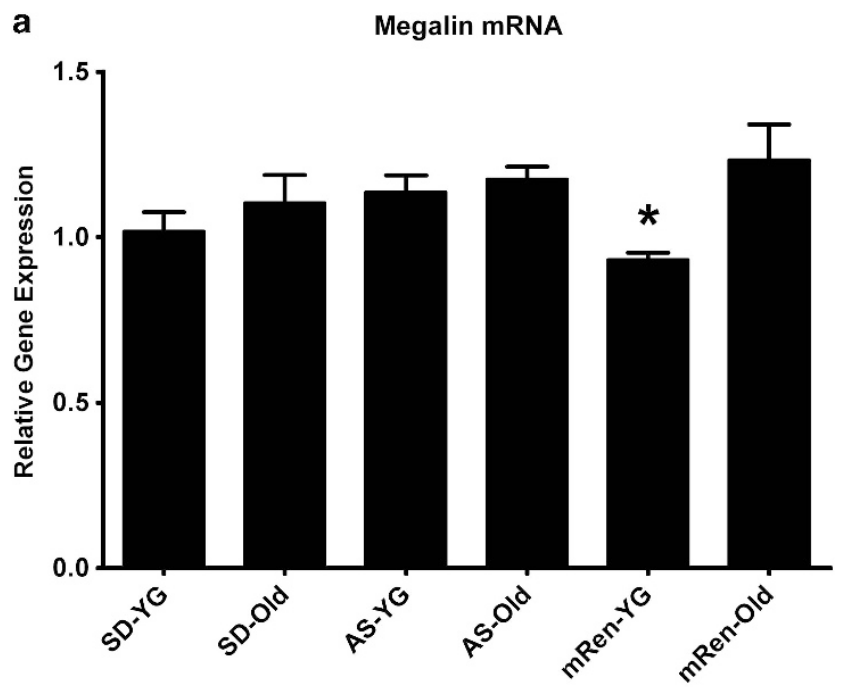

b

PTPN1 mRNA



C

SOCS-3 mRNA

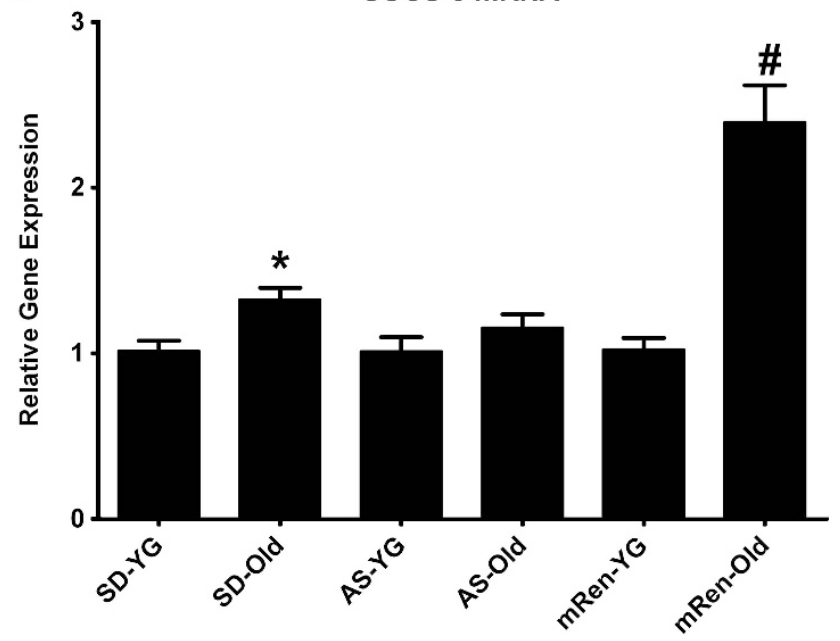

autonomic brain regions ${ }^{111,112}$ that are associated with increased sensitivity to microinjection of cardiovascular and metabolic hormones. ${ }^{113,114}$ Thus, angiotensin II produced from a neuronal source could act on sensitized $\mathrm{AT}_{1}$ receptors to drive increased energy expenditure and promote a positive metabolic profile in ASrAOGEN rats, similar to findings for overexpression of angiotensinogen and renin in neurons of the mice.

\section{ANGIOTENSIN II AND LEPTIN INTERACTIONS FOR AUTONOMIC REGULATION}

There is substantial overlap in the distribution of autonomic pathways participating in regulation of cardiovascular $v s$. metabolic functions. In particular, the anatomic localization of insulin and leptin receptors overlaps with angiotensin receptors in the periphery and in brainstem and hypothalamic sites that influence food intake, glycemic control and cardiovascular regulation. ${ }^{105,106}$ These hormones also utilize similar intracellular signaling pathways, ${ }^{106,115}$ providing a potential site of cross-talk. Recent studies provide evidence that leptin acts within hypothalamic regions to increase sympathetic outflow and elevate blood pressure. ${ }^{116}$ Leptin receptors are also distributed to vagal afferents and within brainstem nuclei such as the nTS and are functional to impair the baroreflex sensitivity for control of heart rate, increase sympathetic outflow to cardiovascular organs and elevate pressure. ${ }^{114,117}$ These data suggest a widespread network for leptin actions that involves multiple brain regions.

In isolated adipocytes from humans and rodents, angiotensin II stimulates leptin production and secretion suggesting a regulatory relationship between these two peptides. ${ }^{118,119}$ In leptin-deficient ob/ob mice, plasma and lung ACE activities are decreased. Systemic restoration of leptin to these animals increases ACE and angiotensin II levels and enhances depressor responses to systemic captopril administration. ${ }^{120}$ Conversely, genetic deletion of ACE reduces circulating leptin in rodents ${ }^{42}$ and chronic treatment with ACE inhibitors and ARBs reduces circulating leptin levels in obese rodents and patients with hypertension. ${ }^{37,121,122}$ In normotensive rats, intracerebroventricular losartan or captopril administration prevents leptin-mediated increases in sympathetic outflow to the kidneys and brown adipose tissue. ${ }^{123}$ Confirming the importance of angiotensin II receptors, sympathetic activation in response to leptin is also attenuated in mice with global deletion of the $\mathrm{AT}_{1 \mathrm{a}}$ receptor. ${ }^{123}$ These data suggest a facilitatory interaction between angiotensin II and leptin for cardiovascular and metabolic actions.

Finally, younger ASrAOGEN rats with lower angiotensin II tone in the nTS for baroreceptor reflex suppression show enhanced responses to nTS microinjection of leptin for effects on baroreflex sensitivity. ${ }^{114}$ The enhanced sensitivity to exogenous leptin is associated with upregulation of leptin receptor and $\mathrm{p} 85 \alpha$ gene expression in dorsal

Figure 3 Metabolic signaling pathway mRNA in dorsal medulla of rats with varying brain RAS activity. Using the methods described in Figure 2, relative gene expression of metabolic signaling components in younger (YG) and older (Old) Sprague-Dawley (SD), ASrAOGEN (AS) and (mRen2)27 (mRen) rats were assessed. (a) Gene expression for megalin, the leptin transporter, was significantly lower in dorsal medulla of younger mRen2 rats ( $P<0.05$ vs. older mRen2 and younger and older AS). (b) Suppressor of cytokine signaling-3 (SOCS-3) mRNA was significantly higher in older vs. younger $S D$ rats ( $P<0.05$ ). Gene expression for SOCS-3 was also higher in older mRen2 rats vs. younger mRen2 and younger and older SD and AS rats ( ${ }^{P}<0.05$ ). (c) PTPN1, the gene encoding PTP1b, was significantly lower in dorsal medulla of older AS rats compared with younger AS and older SD and mRen 2 rats $\left({ }^{*} P<0.05\right)$. 
medulla of these animals (Figure 2). Even during aging, ASrAOGEN rats maintain sensitivity to brainstem leptin injection, in contrast to the loss of leptin actions for baroreflex modulation in older SpragueDawley rats at similar doses. ${ }^{124}$ The maintenance of leptin responses in older ASrAOGEN rats is accompanied by a continued upregulation of brainstem leptin receptor and p $85 \alpha$ mRNA relative to age-matched Sprague-Dawley and (mRen2)27 rats (Figure 2). An enhancement of leptin sensitivity, in the presence of low circulating leptin levels, could contribute to the positive metabolic profile in these animals. Further, the maintenance of low leptin would avoid the deleterious cardiovascular effects of the hormone including sympathetic activation, baroreflex dysfunction and hypertension.

\section{CONCLUSIONS}

There is an increasing need to identify interventions that produce both positive cardiovascular and metabolic outcomes. As the prevalence of elderly individuals increases worldwide, it is critical to understand the mechanisms linking aging, hypertension and related metabolic conditions. Emerging data implicate an important role for the RAS in modulation of autonomic nervous system pathways participating in the regulation of cardiovascular and metabolic functions. The actions of angiotensin II may be especially important to the autonomic imbalance that occurs during aging, which can precipitate elevations in blood pressure and insulin resistance. Indeed, therapies targeting angiotensin II can lower blood pressure, mitigate cardiovascular and renal damage and reduce the incidence of newonset diabetes in essential hypertensive patients, including the elderly. These drugs also improve the decline in cardiovagal baroreflex function characteristic of both aging and hypertension, although the extent to which they involve activation of angiotensin-(1-7) vs. reduction of angiotensin II requires further elucidation. To reduce overall cardiovascular risk, restoration of the balance between these two peptides may be required. Despite a decline in the circulating RAS with aging, ACE inhibitors and ARBs improve lifespan and effectively prevent age-related deficits in rodents, suggesting predominant effects to suppress angiotensin II production from local tissue sources. The brain RAS has received renewed interest in this regard, and findings from transgenic rodents reveal that angiotensin actions within central autonomic pathways may influence a constellation of pathological changes during aging including the development of hypertension and insulin resistance. As downregulation of the glial angiotensinogen produces similar results to chronic systemic treatment with ACE inhibitors and ARBs, it could be speculated that the beneficial effects of these treatments involve direct central actions. In particular, these therapies may influence the balance between angiotensin II and angiotensin-(1-7) within the brainstem, thus determining the prevailing cardiovascular and metabolic function.

\section{CONFLICT OF INTEREST}

The authors declare no conflict of interest.

\section{ACKNOWLEDGEMENTS}

Sources of funding: NIH HL 051952 and Farley Hudson Foundation of Jacksonville, NC.

1 Hotta H, Uchida S. Aging of the autonomic nervous system and possible improvements in autonomic activity using somatic afferent stimulation. Geriatr Gerontol Int 2010; 10(Suppl 1): S127-S136.

2 Ferrari AU, Radaelli A, Centola M. Invited review: aging and the cardiovascular system. J Appl Physiol 2003; 95: 2591-2597.
3 Monahan KD. Effect of aging on baroreflex function in humans. Am J Physiol Regul Integr Comp Physiol 2007; 293: R3-R12.

4 McKinley MJ, Albiston AL, Allen AM, Mathai ML, May CN, McAllen RM, Oldfield BJ, Mendelsohn FA, Chai SY. The brain renin-angiotensin system: location and physiological roles. Int J Biochem Cell Biol 2003; 35: 901-918.

5 Fyhrquist F, Saijonmaa O. Renin-angiotensin system revisited. J Intern Med 2008; 264: 224-236.

6 Ito M, Oliverio MI, Mannon PJ, Best CF, Maeda N, Smithies O, Coffman TM. Regulation of blood pressure by the type $1 \mathrm{~A}$ angiotensin II receptor gene. Proc Natl Acad Sci USA 1995; 92: 3521-3525.

7 Cole J, Ertoy D, Bernstein KE. Insights derived from ACE knockout mice. J Renin Angiotensin Aldosterone Syst 2000; 1: 137-141.

8 Catanzaro DF, Frishman WH. Angiotensin receptor blockers for management of hypertension. South Med J 2010; 103: 669-673.

9 Santos RA, Ferreira AJ, Simoes e Silva AC. Recent advances in the angiotensinconverting enzyme 2-angiotensin(1-7)-Mas axis. Exp Physiol 2008; 93: 519-527.

10 Iyer SN, Ferrario CM, Chappell MC. Angiotensin-(1-7) contributes to the antihypertensive effects of blockade of the renin-angiotensin system. Hypertension 1998; 31(1 Pt 2): 356-361.

11 Benter IF, Ferrario CM, Morris M, Diz DI. Antihypertensive actions of angiotensin(1-7) in spontaneously hypertensive rats. Am J Physiol 1995; 269(1 Pt 2): H313-H319.

12 Benter IF, Yousif MH, Cojocel C, Al-Maghrebi M, Diz DI. Angiotensin-(1-7) prevents diabetes-induced cardiovascular dysfunction. Am J Physiol Heart Circ Physiol 2007; 292: H666-H672.

13 Giani JF, Burghi V, Veiras LC, Tomat A, Munoz MC, Cao G, Turyn D, Toblli JE, Dominici FP. Angiotensin-(1-7) attenuates diabetic nephropathy in Zucker diabetic fatty rats. Am J Physiol Renal Physiol 2012; 302: F1606-F1615.

14 de Moura MM, dos Santos RA, Campagnole-Santos MJ, Todiras M, Bader M, Alenina N, Haibara AS. Altered cardiovascular reflexes responses in conscious Angiotensin(1-7) receptor Mas-knockout mice. Peptides 2010; 31: 1934-1939.

15 Gurley SB, Allred A, Le TH, Griffiths R, Mao L, Philip N, Haystead TA, Donoghue M, Breitbart RE, Acton SL, Rockman HA, Coffman TM. Altered blood pressure responses and normal cardiac phenotype in ACE2-null mice. J Clin Invest 2006; 116: 2218-2225

16 Oudit GY, Kassiri Z, Patel MP, Chappell M, Butany J, Backx PH, Tsushima RG, Scholey JW, Khokha R, Penninger JM. Angiotensin II-mediated oxidative stress and inflammation mediate the age-dependent cardiomyopathy in ACE2 null mice. Cardiovasc Res 2007; 75: 29-39.

17 Crackower MA, Sarao R, Oudit GY, Yagil C, Kozieradzki I, Scanga SE, Oliveira-dosSantos AJ, da Costa J, Zhang L, Pei Y, Scholey J, Ferrario CM, Manoukian AS, Chappell MC, Backx PH, Yagil Y, Penninger JM. Angiotensin-converting enzyme 2 is an essential regulator of heart function. Nature 2002; 417: 822-828.

18 Garcia-Espinosa MA, Shaltout HA, Gallagher PE, Chappell MC, Diz DI. In Vivo Expression of Angiotensin-(1-7) Lowers Blood Pressure and Improves Baroreflex Function in Transgenic (mRen2)27 Rats. J Cardiovasc Pharmacol 2012; 60: 150-157.

19 Shaltout HA, Rose JC, Chappell MC, Diz DI. Angiotensin-(1-7) Deficiency and Baroreflex Impairment Precede the Antenatal Betamethasone Exposure-Induced Elevation in Blood Pressure. Hypertension 2012; 59: 453-458.

20 Diz DI, Garcia-Espinosa MA, Gallagher PE, Ganten D, Ferrario CM, Averill DB. Angiotensin-(1-7) and baroreflex function in nucleus tractus solitarii of (mRen2)27 transgenic rats. J Cardiovasc Pharmacol 2008; 51: 542-548.

21 Diz DI, Kasper SO, Sakima A, Ferrario CM. Aging and the brain renin-angiotensin system: insights from studies in transgenic rats. Cleve Clin J Med 2007; 74(Suppl 1): S95-S98.

22 Ferrario CM, Martell N, Yunis C, Flack JM, Chappell MC, Brosnihan KB, Dean RH, Fernandez A, Novikov SV, Pinillas C, Luque M. Characterization of angiotensin-(1-7) in the urine of normal and essential hypertensive subjects. Am J Hypertens 1998; 11: 137-146.

23 Wakahara S, Konoshita T, Mizuno S, Motomura M, Aoyama C, Makino Y, Kato N, Koni I, Miyamori I. Synergistic expression of angiotensin-converting enzyme (ACE) and ACE2 in human renal tissue and confounding effects of hypertension on the ACE to ACE2 ratio. Endocrinology 2007; 148: 2453-2457.

24 Shaltout HA, Figueroa JP, Rose JC, Diz DI, Chappell MC. Alterations in Circulatory and Renal Angiotensin-Converting Enzyme and Angiotensin-Converting Enzyme 2 in Fetal Programmed Hypertension. Hypertension 2009; 53: 404-408.

25 Shaltout HA, Westwood BM, Averill DB, Ferrario CM, Figueroa JP, Diz DI, Rose JC, Chappell MC. Angiotensin metabolism in renal proximal tubules, urine, and serum of sheep: evidence for ACE2-dependent processing of angiotensin II. Am J Physiol Renal Physiol 2007; 292: F82-F91.

26 Luther JM, Brown NJ. The renin-angiotensin-aldosterone system and glucose homeostasis. Trends Pharmacol Sci 2011; 32: 734-739.

27 Strazzullo P, Galletti F. Impact of the renin-angiotensin system on lipid and carbohydrate metabolism. Curr Opin Nephrol Hypertens 2004; 13: 325-332.

28 Giacchetti G, Faloia E, Mariniello B, Sardu C, Gatti C, Camilloni MA, Guerrieri M, Mantero F. Overexpression of the renin-angiotensin system in human visceral adipose tissue in normal and overweight subjects. Am J Hypertens 2002; 15: 381-388.

29 Hainault I, Nebout G, Turban S, Ardouin B, Ferre P, Quignard-Boulange A. Adipose tissue-specific increase in angiotensinogen expression and secretion in the obese (fa/ fa) Zucker rat. Am J Physiol Endocrinol Metab 2002; 282: E59-E66.

30 Massiera F, Bloch-Faure M, Ceiler D, Murakami K, Fukamizu A, Gasc JM, QuignardBoulange A, Negrel R, Ailhaud G, Seydoux J, Meneton P, Teboul M. Adipose 
angiotensinogen is involved in adipose tissue growth and blood pressure regulation. FASEB J 2001; 15: 2727-2729.

31 Yvan-Charvet L, Quignard-Boulange A. Role of adipose tissue renin-angiotensin system in metabolic and inflammatory diseases associated with obesity. Kidney Int 2011; 79: 162-168.

32 Engeli S, Bohnke J, Gorzelniak K, Janke J, Schling P, Bader M, Luft FC, Sharma AM. Weight loss and the renin-angiotensin-aldosterone system. Hypertension 2005; 45 356-362.

33 Strazzullo P, lacone R, lacoviello L, Russo O, Barba G, Russo P, D’Orazio A, Barbato A, Cappuccio FP, Farinaro E, Siani A. Genetic variation in the renin-angiotensin system and abdominal adiposity in men: the Olivetti Prospective Heart Study. Ann Intern Med 2003; 138: 17-23.

34 Chaves FJ, Giner V, Corella D, Pascual J, Marin P, Armengod ME, Redon J. Body weight changes and the A-6G polymorphism of the angiotensinogen gene. Int J Obes Relat Metab Disord 2002; 26: 1173-1178.

35 Stucchi P, Cano V, Ruiz-Gayo M, Fernandez-Alfonso MS. Aliskiren reduces bodyweight gain, adiposity and plasma leptin during diet-induced obesity. $\mathrm{Br} J$ Pharmacol 2009; 158: 771-778.

36 Weisinger RS, Stanley TK, Begg DP, Weisinger HS, Spark KJ, Jois M. Angiotensin converting enzyme inhibition lowers body weight and improves glucose tolerance in C57BL/6J mice maintained on a high fat diet. Physiol Behav 2009; 98: 192-197.

37 Velkoska E, Warner FJ, Cole TJ, Smith I, Morris MJ. Metabolic effects of low dose angiotensin converting enzyme inhibitor in dietary obesity in the rat. Nutr Metab Cardiovasc Dis 2010; 20: 49-55.

38 Chou CL, Lai YH, Lin TY, Lee TJ, Fang TC. Aliskiren prevents and ameliorates metabolic syndrome in fructose-fed rats. Arch Med Sci 2011; 7: 882-888.

39 Massiera F, Seydoux J, Geloen A, Quignard-Boulange A, Turban S, Saint-Marc P, Fukamizu A, Negrel R, Ailhaud G, Teboul M. Angiotensinogen-deficient mice exhibit impairment of diet-induced weight gain with alteration in adipose tissue development and increased locomotor activity. Endocrinology 2001; 142: 5220-5225.

40 Kouyama R, Suganami T, Nishida J, Tanaka M, Toyoda T, Kiso M, Chiwata T, Miyamoto Y, Yoshimasa Y, Fukamizu A, Horiuchi M, Hirata Y, Ogawa Y. Attenuation of diet-induced weight gain and adiposity through increased energy expenditure in mice lacking angiotensin II type 1a receptor. Endocrinology 2005; 146: 3481-3489.

41 Takahashi N, Li F, Hua K, Deng J, Wang CH, Bowers RR, Bartness TJ, Kim HS, Harp JB. Increased energy expenditure, dietary fat wasting, and resistance to diet-induced obesity in mice lacking renin. Cell Metab 2007; 6: 506-512.

42 Jayasooriya AP, Mathai ML, Walker LL, Begg DP, Denton DA, Cameron-Smith D, Egan GF, McKinley MJ, Rodger PD, Sinclair AJ, Wark JD, Weisinger HS, Jois M, Weisinge RS. Mice lacking angiotensin-converting enzyme have increased energy expenditure, with reduced fat mass and improved glucose clearance. Proc Natl Acad Sci USA 2008; 105: 6531-6536.

43 Hershon KS. Mechanistic and clinical aspects of renin-angiotensin-aldosterone system blockade in the prevention of diabetes mellitus and cardiovascular disease. Endocr Pract 2011; 17: 430-440.

44 Cassis LA, Marshall DE, Fettinger MJ, Rosenbluth B, Lodder RA. Mechanisms contributing to angiotensin II regulation of body weight. Am J Physiol 1998; 274(5 Pt 1): E867-E876

45 de Kloet AD, Krause EG, Scott KA, Foster MT, Herman JP, Sakai RR, Seeley RJ, Woods SC. Central angiotensin II has catabolic action at white and brown adipose tissue. Am J Physiol Endocrinol Metab 2011; 301: E1081-E1091.

46 Fliser D, Schaefer F, Schmid D, Veldhuis JD, Ritz E. Angiotensin II affects basal, pulsatile, and glucose-stimulated insulin secretion in humans. Hypertension 1997 30: 1156-1161.

47 Fliser D, Arnold U, Kohl B, Hartung R, Ritz E. Angiotensin II enhances insulin sensitivity in healthy volunteers under euglycemic conditions. J Hypertens 1993; 11 983-988.

48 Lindholm LH, Ibsen H, Borch-Johnsen K, Olsen MH, Wachtell K, Dahlof B, Devereux RB, Beevers G, de FU, Fyhrquist F, Julius S, Kjeldsen SE, Kristianson K, LederballePedersen O, Nieminen MS, Omvik P, Oparil S, Wedel H, Aurup P, Edelman JM, Snapinn S. Risk of new-onset diabetes in the Losartan Intervention For Endpoint reduction in hypertension study. J Hypertens 2002; 20: 1879-1886.

49 Julius S, Kjeldsen SE, Weber M, Brunner HR, Ekman S, Hansson L, Hua T, Laragh J, McInnes GT, Mitchell L, Plat F, Schork A, Smith B, Zanchetti A. Outcomes in hypertensive patients at high cardiovascular risk treated with regimens based on valsartan or amlodipine: the VALUE randomised trial. Lancet 2004; 363: 2022-2031.

50 ALLHAT Officers and Coordinators for the ALLHAT Collaborative Research Group. The Antihypertensive and Lipid-Lowering Treatment to Prevent Heart Attack Trial. Major outcomes in high-risk hypertensive patients randomized to angiotensin-converting enzyme inhibitor or calcium channel blocker vs diuretic: The Antihypertensive and Lipid-Lowering Treatment to Prevent Heart Attack Trial (ALLHAT). JAMA 2002; 288: 2981-2997.

51 Munoz MC, Giani JF, Dominici FP. Angiotensin-(1-7) stimulates the phosphorylation of Akt in rat extracardiac tissues in vivo via receptor Mas. Regul Pept 2010; 161: $1-7$.

52 Santos SH, Fernandes LR, Mario EG, Ferreira AV, Porto LC, Alvarez-Leite JI, Botion LM, Bader M, Alenina N, Santos RA. Mas deficiency in FVB/N mice produces marked changes in lipid and glycemic metabolism. Diabetes 2008; 57: 340-347.

53 Bindom SM, Lazartigues E. The sweeter side of ACE2: Physiological evidence for a role in diabetes. Mol Cell Endocrinol 2009; 302: 193-202.

54 Santos SH, Braga JF, Mario EG, Porto LC, Rodrigues-Machado MG, Murari A, Botion LM, Alenina N, Bader M, Santos RA. Improved lipid and glucose metabolism in transgenic rats with increased circulating angiotensin-(1-7). Arterioscler Thromb Vasc Biol 2010; 30: 953-961.

55 Bindom SM, Hans $\mathrm{CP}$, Xia $\mathrm{H}$, Boulares $\mathrm{AH}$, Lazartigues $\mathrm{E}$, Angiotensin $I \Gamma$. ÇôConverting enzyme type 2 (ACE2) gene therapy improves glycemic control in diabetic mice. Diabetes 2010; 59: 2540--22548.

56 Feng Y, Xia H, Santos RA, Speth R, Lazartigues E. Angiotensin-converting enzyme 2: a new target for neurogenic hypertension. Exp Physiol 2010; 95: 601-606.

57 Sakima A, Averill DB, Gallagher PE, Kasper SO, Tommasi EN, Ferrario CM, Diz DI. Impaired heart rate baroreflex in older rats: role of endogenous angiotensin-(1-7) at the nucleus tractus solitarii. Hypertension 2005; 46: 333-340.

58 Itoh H, Bunag RD. Age-related reduction of reflex bradycardia in conscious rats by catecholaminergic nucleus tractus solitarius lesions. Mech Ageing Dev 1993; 67 47-63.

59 Garcia-Espinosa MA, Shaltout HA, Olson J, Westwood BM, Robbins ME, Link K, Diz DI. Proton magnetic resonance spectroscopy detection of neurotransmitters in dorsomedial medulla correlate with spontaneous baroreceptor reflex function. Hypertension 2010; 55: 487-493.

60 Diz DI, Garcia-Espinosa MA, Shaltout HA, Olson J, Bourland JD, Groban L. Correlation of the brain medullary metabolites $\mathrm{N}$-acetyl aspartic acid and $\mathrm{N}$-acety aspartyl glutamate with the age related decline in sensitivity for baroreflex control of heart rate in humans. Hypertension 2011; 58: e116 (Abstract).

61 Thayer JF, Lane RD. The role of vagal function in the risk for cardiovascular disease and mortality. Biol Psychol 2007; 74: 224-242.

62 Kulminski AM, Culminskaya IV, Ukraintseva SV, Arbeev KG, Akushevich I, Land KC Yashin Al. Polymorphisms in the ACE and ADRB2 genes and risks of aging-associated phenotypes: the case of myocardial infarction. Rejuvenation Res 2010; 13: 13-21.

63 Mohamed MA, Weir MR. Renin angiotensin system inhibition in the older person: review. Clin Geriatr Med 2009; 25: 245-257.

64 Basso N, Paglia N, Stella I, de Cavanagh EM, Ferder L, del Rosario Lores AM, Inserra F. Protective effect of the inhibition of the renin-angiotensin system on aging. Regul Pept 2005; 128: 247-252.

65 Benigni A, Corna D, Zoja C, Sonzogni A, Latini R, Salio M, Conti S, Rottoli D, Longaretti L, Cassis P, Morigi M, Coffman TM, Remuzzi G. Disruption of the Ang II type 1 receptor promotes longevity in mice. J Clin Invest 2009; 119: 524-530.

66 Modrick ML, Didion SP, Sigmund CD, Faraci FM. Role of oxidative stress and AT1 receptors in cerebral vascular dysfunction with aging. Am J Physiol Heart Circ Physiol 2009; 296: H1914-H1919.

67 Kaneko K, Ito M, Fumoto T, Fukuhara R, Ishida J, Fukamizu A, Ikeda K. Physiological function of the angiotensin ATla receptor in bone remodeling. J Bone Miner Res 2011; 26: 2959-2966.

68 Oudit GY, Liu GC, Zhong J, Basu R, Chow FL, Zhou J, Loibner H, Janzek E, Schuster M, Penninger JM, Herzenberg AM, Kassiri Z, Scholey JW. Human recombinant ACE2 reduces the progression of diabetic nephropathy. Diabetes 2010; 59: 529-538.

69 Xia H, Suda S, Bindom S, Feng Y, Gurley SB, Seth D, Navar LG, Lazartigues E. ACE2 mediated reduction of oxidative stress in the central nervous system is associated with improvement of autonomic function. PLoS One 2011; 6: e22682.

70 Gilliam-Davis S, Payne VS, Kasper So, Tommasi EN, Robbins ME, Diz DI. Long-term AT1 receptor blockade improves metabolic function and provides renoprotection in Fischer-344 rats. Am J Physiol Heart Circ Physiol 2007; 293: H1327-H1333.

71 Gilliam-Davis S, Gallagher PE, Payne VS, Kasper SO, Tommasi EN, Westwood BM, Robbins ME, Chappell MC, Diz DI. Long-term systemic angiotensin II type 1 receptor blockade regulates mRNA expression of dorsomedial medulla renin-angiotensin system components. Physiol Genomics 2011; 43: 829-835.

72 Anderson S. Ageing and the renin-angiotensin system. Nephrol Dial Transplant 1997; 12: 1093-1094

73 Diz DI, Lewis K. Dahl memorial lecture: the renin-angiotensin system and aging. Hypertension 2008; 52: 37-43.

74 Britto RR, Santos RA, Fagundes-Moura CR, Khosla MC, Campagnole-Santos MJ. Role of angiotensin-(1-7) in the modulation of the baroreflex in renovascular hypertensive rats. Hypertension 1997; 30(3 Pt 2): 549-556.

75 Diz DI, Jessup JA, Westwood BM, Bosch SM, Vinsant S, Gallagher PE, Averill DB Angiotensin peptides as neurotransmitters/neuromodulators in the dorsomedial medulla. Clin Exp Pharmacol Physiol 2002; 29: 473-482.

76 Dupont AG, Brouwers S. Brain angiotensin peptides regulate sympathetic tone and blood pressure. J Hypertens 2010; 28: 1599-1610.

77 Campagnole-Santos MJ, Diz DI, Ferrario CM. Baroreceptor reflex modulation by angiotensin II at the nucleus tractus solitarii. Hypertension 1988; 11(2 Pt 2): |167-|171.

78 Casto R, Phillips MI. Angiotensin II attenuates baroreflexes at nucleus tractus solitarius of rats. Am J Physiol 1986; 250(2 Pt 2): R193-R198.

79 Oliveira DR, Santos RA, Santos GF, Khosla M, Campagnole-Santos MJ. Changes in the baroreflex control of heart rate produced by central infusion of selective angiotensin antagonists in hypertensive rats. Hypertension 1996; 27: 1284-1290.

80 Chaves GZ, Caligiorne SM, Santos RA, Khosla MC, Campagnole-Santos MJ. Modula tion of the baroreflex control of heart rate by angiotensin-(1-7) at the nucleus tractus solitarii of normotensive and spontaneously hypertensive rats. J Hypertens 2000; 18 1841-1848.

81 Campagnole-Santos MJ, Diz DI, Santos RA, Khosla MC, Brosnihan KB, Ferrario CM Cardiovascular effects of angiotensin-(1-7) injected into the dorsal medulla of rats. Am J Physiol 1989; 257(1 Pt 2): H324-H329.

82 Diz DI, Garcia-Espinosa MA, Gegick S, Tommasi EN, Ferrario CM, Ann TE, Chappell $\mathrm{MC}$, Gallagher PE. Injections of angiotensin-converting enzyme 2 inhibitor MLN4760 
into nucleus tractus solitarii reduce baroreceptor reflex sensitivity for heart rate control in rats. Exp Physiol 2008; 93: 694-700.

83 Ferrari AU, Daffonchio A, Albergati F, Mancia G. Differential effects of aging on the heart rate and blood pressure influences of arterial baroreceptors in awake rats. $J$ Hypertens 1991; 9: 615-621.

84 Kasper SO, Carter CS, Ferrario CM, Ganten D, Ferder LF, Sonntag WE, Gallagher PE, Diz DI. Growth, metabolism, and blood pressure disturbances during aging in transgenic rats with altered brain renin-angiotensin systems. Physiol Genomics 2005; 23: 311-317.

85 Bachmann S, Peters J, Engler E, Ganten D, Mullins J. Transgenic rats carrying the mouse renin gene-morphological characterization of a low-renin hypertension model. Kidney Int 1992; 41: 24-36.

86 Isa K, Arnold AC, Westwood BM, Chappell MC, Diz DI. Angiotensin-converting enzyme inhibition, but not AT(1) receptor blockade, in the solitary tract nucleus improves baroreflex sensitivity in anesthetized transgenic hypertensive (mRen2)27 rats. Hypertens Res 2011; 34: 1257-1262.

87 Nautiyal M, Shaltout HA, Chappell MC, Diz DI. Chronic intracerebroventricular angiotensin-(1-7) infusion, but not AT1 receptor blockade, improves vagal components of the baroreflex function in hypertensive (mRen2)27 transgenic rats. Hypertension 2011; 58: e96 (Abstract).

88 Seyedabadi M, Goodchild AK, Pilowsky PM. Differential role of kinases in brain stem of hypertensive and normotensive rats. Hypertension 2001; 38: 1087-1092.

89 Logan EM, Aileru AA, Shaltout HA, Averill DB, Diz DI. The functional role of PI3K in maintenance of blood pressure and baroreflex suppression in (mRen2)27 and mRen2.Lewis rat. J Cardiovasc Pharmacol 2011; 58: 367-373.

90 Grobe JL, Grobe CL, Beltz TG, Westphal SG, Morgan DA, Xu D, de Lange WJ, Li H, Sakai K, Thedens DR, Cassis LA, Rahmouni K, Mark AL, Johnson AK, Sigmund CD. The brain Renin-angiotensin system controls divergent efferent mechanisms to regulate fluid and energy balance. Cell Metab 2010; 12: 431-442.

91 Schinke M, Baltatu O, Bohm M, Peters J, Rascher W, Bricca G, Lippoldt A, Ganten D, Bader M. Blood pressure reduction and diabetes insipidus in transgenic rats deficient in brain angiotensinogen. Proc Natl Acad Sci USA 1999; 96: 3975-3980.

92 Stornetta RL, Hawelu-Johnson CL, Guyenet PG, Lynch KR. Astrocytes synthesize angiotensinogen in brain. Science 1988; 242: 1444-1446.

93 Vinsant S, Chappell MC, Ferrario CM, Ganten D, Diz DI. Low glial angiotensinogen is not associated with deficits in angiotensin peptides in neuronal pathways in transgenic ASrAogen rats. FASEB J 2005; 19: A1188 (Abstract).

94 Baltatu O, Janssen BJ, Bricca G, Plehm R, Monti J, Ganten D, Bader M. Alterations in blood pressure and heart rate variability in transgenic rats with low brain angiotensinogen. Hypertension 2001; 37(2 Part 2): 408-413.

95 Sakima A, Averill DB, Kasper SO, Jackson L, Ganten D, Ferrario CM, Gallagher PE, Diz DI. Baroreceptor reflex regulation in anesthetized transgenic rats with low glia-derived angiotensinogen. Am J Physiol Heart Circ Physiol 2007; 292: $\mathrm{H} 1412-\mathrm{H} 1419$.

96 Caligiorne SM, Silva $A Q$, Fontes MA, Silva JR, Baltatu O, Bader M, Santos RA, Campagnole-Santos MJ. Baroreflex control of heart rate and renal sympathetic nerve activity in rats with low brain angiotensinogen. Neuropeptides 2008; 42: 159-168.

97 Arnold AC, Sakima A, Ganten D, Ferrario CM, Diz DI. Modulation of reflex function by endogenous angiotensins in older transgenic rats with low glial angiotensinogen. Hypertension 2008; 51: 1326-1331.

98 Sakai K, Chapleau MW, Morimoto S, Cassell MD, Sigmund CD. Differential modulation of baroreflex control of heart rate by neuron- vs. glia-derived angiotensin II. Physiol Genomics 2004; 20: 66-72.

99 Bonini JS, Bevilaqua LR, Zinn CG, Kerr DS, Medina JH, Izquierdo I, Cammarota M. Angiotensin II disrupts inhibitory avoidance memory retrieval. Horm Behav 2006; 50 308-313.

100 Carter CS, Cesari M, Ambrosius WT, Hu N, Diz D, Oden S, Sonntag WE, Pahor M. Angiotensin-converting enzyme inhibition, body composition, and physical performance in aged rats. J Gerontol A Biol Sci Med Sci 2004; 59: 416-423.

101 de Cavanagh EM, Inserra F, Ferder L. Angiotensin II blockade: a strategy to slow ageing by protecting mitochondria? Cardiovasc Res 2011; 89: 31-40.

102 Sink KM, Leng X, Williamson J, Kritchevsky SB, Yaffe K, Kuller L, Yasar S, Atkinson H, Robbins M, Psaty B, Goff Jr DC. Angiotensin-converting enzyme inhibitors and cognitive decline in older adults with hypertension: results from the Cardiovascular Health Study. Arch Intern Med 2009; 169: 1195-1202.

103 Labandeira-Garcia JL, Rodriguez-Pallares J, Villar-Cheda B, Rodriguez-Perez Al, Garrido-Gil P, Guerra MJ. Aging, Angiotensin system and dopaminergic degeneration in the substantia nigra. Aging Dis 2011; 2: 257-274.

104 Wright JW, Harding JW. The brain RAS and Alzheimer's disease. Exp Neurol 2010; 223: 326-333.

105 Elmquist JK, Ahima RS, Maratos-Flier E, Flier JS, Saper CB. Leptin activates neurons in ventrobasal hypothalamus and brainstem. Endocrinology 1997; 138: 839-842.

106 Porte Jr. D, Baskin DG, Schwartz MW. Leptin and insulin action in the central nervous system. Nutr Rev 2002; 60(10 Pt 2): S20-S29.

107 Kasper SO, Ferrario CM, Ganten D, Diz DI. Rats with low brain angiotensinogen do not exhibit insulin resistance during early aging. Endocrine 2006; 30: 167-174.

108 Dietrich MO, Spuch C, Antequera D, Rodal I, de Yebenes JG, Molina JA, Bermejo F, Carro E. Megalin mediates the transport of leptin across the blood-CSF barrier. Neurobiol Aging 2008; 29: 902-912.

109 Koren S, Fantus IG. Inhibition of the protein tyrosine phosphatase PTP1B: potential therapy for obesity, insulin resistance and type-2 diabetes mellitus. Best Pract Res Clin Endocrinol Metab 2007; 21: 621-640.

110 Morrison CD, White CL, Wang Z, Lee SY, Lawrence DS, Cefalu WT, Zhang ZY, Gettys TW. Increased hypothalamic protein tyrosine phosphatase 1B contributes to leptin resistance with age. Endocrinology 2007; 148: 433-440.

111 Monti J, Schinke M, Bohm M, Ganten D, Bader M, Bricca G. Glial angiotensinogen regulates brain angiotensin II receptors in transgenic rats TGR(ASrAOGEN). Am J Physiol Regul Integr Comp Physiol 2001; 280: R233-R240.

112 Kasper SO, Ferrario CM, Ganten D, Diz DI. Central depletion of angiotensinogen is associated with elevated AT1 receptors in the SFO and PVN. Neurotox Res 2004; 6: 259-265.

113 Couto AS, Baltatu O, Santos RA, Ganten D, Bader M, Campagnole-Santos MJ. Differential effects of angiotensin II and angiotensin-(1-7) at the nucleus tractus solitarii of transgenic rats with low brain angiotensinogen. J Hypertens 2002; 20: 919-925.

114 Arnold AC, Shaltout HA, Gallagher PE, Diz DI. Leptin impairs cardiovagal baroreflex function at the level of the solitary tract nucleus. Hypertension 2009; 54: 1001-1008.

115 Mehta PK, Griendling KK. Angiotensin II cell signaling: physiological and pathological effects in the cardiovascular system. Am J Physiol Cell Physiol 2007; 292: C82-C97.

116 Rahmouni K, Haynes WG, Mark AL. Cardiovascular and sympathetic effects of leptin. Curr Hypertens Rep 2002; 4: 119-125.

117 Mark AL, Agassandian K, Morgan DA, Liu X, Cassell MD, Rahmouni K. Leptin signaling in the nucleus tractus solitarii increases sympathetic nerve activity to the kidney. Hypertension 2009; 53: 375-380.

118 Kim S, Whelan J, Claycombe K, Reath DB, Moustaid-Moussa N. Angiotensin II increases leptin secretion by 3T3-L1 and human adipocytes via a prostaglandinindependent mechanism. J Nutr 2002; 132: 1135-1140.

119 Cassis LA, English VL, Bharadwaj K, Boustany CM. Differential effects of local versus systemic angiotensin $I I$ in the regulation of leptin release from adipocytes. Endocrinology 2004; 145: 169-174.

120 Hilzendeger AM, Morais RL, Todiras M, Plehm R, da Costa GA, Qadri F, Araujo RC Gross V, Nakaie CR, Casarini DE, Carmona AK, Bader M, Pesquero JB. Leptin regulates ACE activity in mice. J Mol Med (Berl) 2010; 88: 899-907.

121 Koh KK. Distinct metabolic effects of different classes of antihypertensive drugs. Hypertension 2009; 53: e26.

122 Fogari R, Derosa G, Zoppi A, Rinaldi A, Lazzari P, Fogari E, Mugellini A, Preti P. Comparison of the effects of valsartan and felodipine on plasma leptin and insulin sensitivity in hypertensive obese patients. Hypertens Res 2005; 28: 209-214.

123 Hilzendeger AM, Morgan DA, Brooks L, Dellsperger D, Liu X, Grobe JL, Rahmouni K, Sigmund $C D$, Mark ALA. Brain leptin-renin angiotensin system interaction in the regulation of sympathetic nerve activity. Am J Physiol Heart Circ Physiol 2012; 303: H197-H206.

124 Arnold AC, Diz DI. Endogenous leptin within the solitary tract nucleus contributes to age-related baroreflex suppression in older anesthetized sprague-dawley rats Hypertension 2010; 56: e72 (Abstract). 